\title{
Study of The Phenomena of Surface Discharges and Flashover in Nanocomposite Epoxy Resin under the Influence of Homogeneous Electric Fields
}

\author{
D. Verginadis \\ Democritus University of Thrace, \\ Department of Electrical and Computer \\ Engineering, Xanthi, Greece \\ dimoverg2@ee.duth.gr
}

\author{
M. G. Danikas \\ Democritus University of Thrace, \\ Department of Electrical and Computer \\ Engineering, Xanthi, Greece \\ mdanikas@ee.duth.gr
}

\author{
R. Sarathi \\ Indian Institute of Technology Madras \\ Department of Electrical Engineering \\ Chennai, India \\ sarathi@ee.iitm.ac.in
}

\begin{abstract}
A new class of insulating materials is the class of polymer nanocomposites. In the past twenty-five years, a lot of attention was paid to the various electrical, thermal and mechanical properties of polymer nanocomposite materials. In the present work, epoxy resin samples without and with nanoparticles $(0 \mathrm{wt} \%, 1 \mathrm{wt} \%, 3 \mathrm{wt} \%, 5 \mathrm{wt} \%$, and $10 \mathrm{wt} \%)$ are investigated regarding the surface discharges and the flashover voltages. Four different water droplet arrangements were used, with eight different water conductivities in order to see the effect of the nanoparticle content on the surface discharges and the flashover voltages.
\end{abstract}

Keywords-polymer nanocomposites; nanoparticles; surface discharges; flashover voltage

\section{INTRODUCTION}

A nanocomposite is defined as a material having constituents, one of which has dimensions in the nanorange. Intensive research in the field of nanocomposites started especially after the publication of [1]. Numerous other publications followed explaining the workings of such materials [2, 3]. Models have been proposed and commented upon regarding the behavior of the polymer nanocomposites $[4$, 5]. It was shown that polymer nanocomposites present improved electrical, thermal and mechanical properties compared with the respective conventional polymers. Polymer nanocomposites have been applied in various industries, such as the automobile industry, the building industry and the food industry. Although much research has been carried out on various aspects of polymer nanocomposites, relatively little is known w.r.t. their surface discharge and flashover behavior [6]. As reported before, surface phenomena in polymer nanocomposites are important because they determine to a significant extent their behavior in indoor as well as in outdoor high voltage applications [7]. Surface discharges and consequently the flashover phenomenon are due, among other factors, to the presence of water droplets on the polymer nanocomposite surface. It is the aim of this paper to investigate the influence of various water droplet arrangements, with various water conductivities, under uniform electrical fields on epoxy resin nanocomposite surfaces. A sample with no nanoparticles at all was used as reference. The epoxy resin nanocomposites contained nanoparticles of percentages $1 \mathrm{wt} \%$, $3 \mathrm{wt} \%, 5 \mathrm{wt} \%$ and $10 \mathrm{wt} \%$. The present work continues previous work conducted with the same samples [7].

\section{WATER DROPLET BEHAVIOR}

Water droplets on an insulating surface under the influence of an electrical field tend to deform. Surface discharges follow such deformation. Dry zones may ensue, then local arcs and finally a flashover. Such a sequence of events is more or less common in both indoor and outdoor high voltage applications, although there are some differences [8,9]. When a droplet becomes unstable because of a deformation, tiny droplets may be rocketed from it. The initial droplet oscillates violently and the tiny droplets are highly charged. The main droplet becomes smaller in size as well as in electric charge. Under an electric field this is an ongoing process which may lead to intense surface discharging, formation of dry zones and then local arcing. Relevant research performed in the past revealed that, in the case of polymer nanocomposites, the contact angle of the water droplet increases with the increase of the nanoparticle content and that the positioning of the droplet w.r.t. the electrodes is also important $[10,11]$.

\section{EXPERIMENTAL ARRANGEMENT AND INSULATING MATERIALS}

The experimental arrangement used is described in detail in earlier publications $[7,12]$ and only a brief mention will be given here. The voltage was supplied from a $20 \mathrm{kV}$ transformer. The electrodes were made of copper and had a half cylindrical shape with rounded edges. Needless to say that care was taken so that their surfaces were very smooth. The water droplets are shown in Figures 1-4, and they were positioned on the sample in four different arrangements. It must be emphasized that two of the droplet arrangements in the present paper (those of Figures 3 and 4) are different from the ones described in [7]. Eight different water conductivities were used, namely $1.4 \mu \mathrm{S} / \mathrm{cm}, \quad 100 \mu \mathrm{S} / \mathrm{cm}, 200 \mu \mathrm{S} / \mathrm{cm}, 500 \mu \mathrm{S} / \mathrm{cm}, 1000 \mu \mathrm{S} / \mathrm{cm}$, $2000 \mu \mathrm{S} / \mathrm{cm}, 5000 \mu \mathrm{S} / \mathrm{cm}$ and $10000 \mu \mathrm{S} / \mathrm{cm}$. In Figure 1, one droplet of volume $0.05 \mathrm{ml}$ (or $0.1 \mathrm{ml}$ ) was put at a distance of 
$1.25 \mathrm{~cm}$ from the electrodes. In Figure 2, two droplets (each of $0.05 \mathrm{ml}$ or $0.1 \mathrm{ml}$ ) were positioned one next to the other at a distance of $0.8 \mathrm{~cm}$ between them and $0.8 \mathrm{~cm}$ from the electrodes. In Figure 3, two droplets were positioned one on top of the other of $0.05 \mathrm{ml}$ (or of $0.1 \mathrm{ml}$ ) at a distance of $1.25 \mathrm{~cm}$ from the electrodes and at a distance of $1 \mathrm{~cm}$ from each other. In Figure 4, three droplets were positioned, each of $0.05 \mathrm{ml}$ (or $0.1 \mathrm{ml}$ ) at a distance of $1.25 \mathrm{~cm}$ from the electrodes.

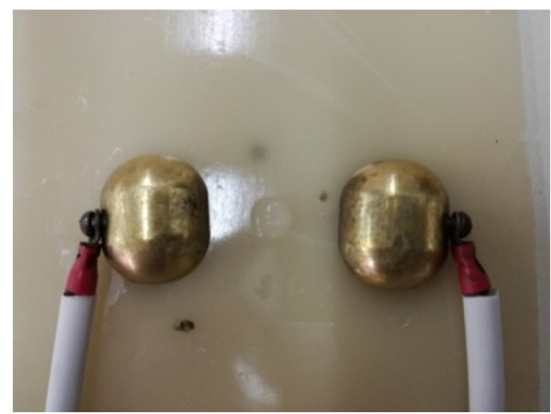

Fig. 1. One-droplet arrangement

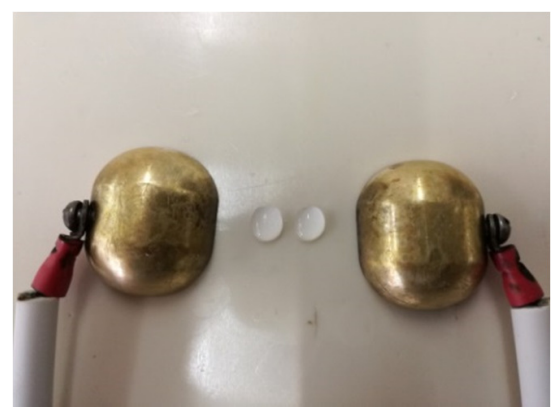

Fig. 2. Two-droplets arrangement

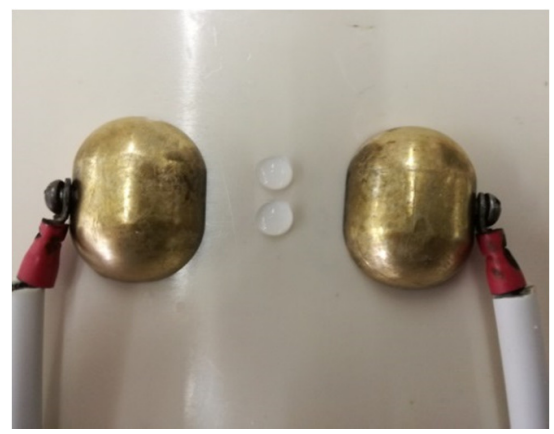

Fig. 3. Two-droplets arrangement

The polymer nanocomposite used was epoxy resin plates having nanoparticles with $1 \mathrm{wt} \%, 3 \mathrm{wt} \%, 5 \mathrm{wt} \%$ and $10 \mathrm{wt} \%$. A reference sample with no nanoparticles at all was also used.The epoxy nanocomposite was synthesized by mechanical shear mixing of organo-clay in the resin bath at room temperature. The high speed shear mixer consists of an impeller which rotates at a high speed of 2000rpm. The clay mineral used was organophilic montmorillonite (MMT) procured from Southern Clay products Inc. (Gonzales, Texas) with the trade name of Garamite1958 (colour: off white, bulk density: $1.5-1.7 \mathrm{~g} / \mathrm{cc}$, weight loss at 10000C: $37 \%$, d spacing at d001: $17.2 \AA$ ).

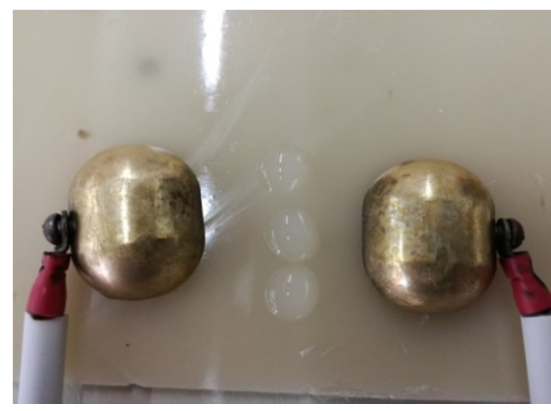

Fig. 4. Three-droplets arrangement

After uniform mixing of MMT clay in epoxy resin (which was DGEBA, CY205, Ciba Geigy Inc.), $10 \mathrm{wt} \%$ of triethylenetetramine (TETA) hardener was added and then casted in a mould of required dimension and then degassed. The MMT clay belongs to a family of 2:1 layered silicates. Epoxy nanocomposites of $3 \mathrm{~mm}$ thickness with different percentages $(1-10 \%)$ of clay were prepared [7]. The surface roughness of the samples was measured with a Perthen device (Perthometer M4P) and it gave the following results (minimum-maximum roughness): for the $0 \mathrm{wt} \%$ (reference) sample from $0.59 \mu \mathrm{m}$ to $0.69 \mu \mathrm{m}$, for the $1 \mathrm{wt} \%$ sample from $0.60 \mu \mathrm{m}$ to $0.79 \mu \mathrm{m}$, for $3 \mathrm{wt} \%$ sample from $0.49 \mu \mathrm{m}$ to $0.59 \mu \mathrm{m}$, for the $5 \mathrm{wt} \%$ sample from $0.60 \mu \mathrm{m}$ to $0.68 \mu \mathrm{m}$ and for the $10 \mathrm{wt} \%$ sample from $0.22 \mu \mathrm{m}$ to $0.22 \mu \mathrm{m}$.

\section{EXPERIMENTAL METHOD}

The parameters investigated in this work were the water conductivity, the number of droplets, the droplet volume and the positioning of the droplets w.r.t. the electrodes. The experimental method followed was the same as in previous papers [7] and it will briefly be given here: the droplet(s) were put on the polymer surface. Then the voltage was raised until flashover happened. After that, new droplet(s) of the same number, volume and positioning were put on the surface and the voltage was raised up to a voltage which was lower by $1.2 \mathrm{kV}$ from the previous flashover. At this voltage the whole arrangement would stay for 5 minutes. If no flashover occurred, the voltage was raised by further $0.4 \mathrm{kV}$ and kept for another 5 minutes and this went on until flashover occurred. That was the flashover that was recorded. The reason the voltage was allowed to stay for 5 minutes at each value was because we wanted to see whether the droplet (or droplets) were deforming and whether surface discharging was starting. As in the previous publication [7], we thought that 5 minutes was enough time in order to see the oscillation and eventual deformation of the droplet(s), the development of surface discharges and the actual flashover. Needless to say that for every new experiment, the electrodes were meticulously cleaned. The distance between the electrodes in all experiments was set at $2.5 \mathrm{~cm}$. The droplets were put on the polymer surface with the aid of a syringe. Different syringes were used for the different water conductivities. Flashover occurred either through the air (Figure 5) or through the droplets (Figure 6).

\section{EXPERIMENTAL RESULTS}

Figure 7 shows the variation of flashover voltage with water conductivity for one droplet of $0.05 \mathrm{ml}$. Figure 8 shows the 
variation of flashover voltage with water conductivity for two droplets next to each other, each having a volume of $0.05 \mathrm{ml}$.

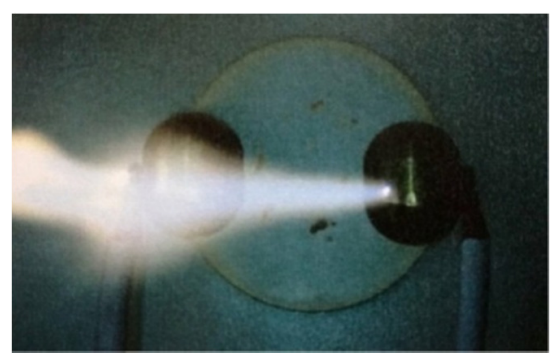

Fig. 5. Flashover through the air

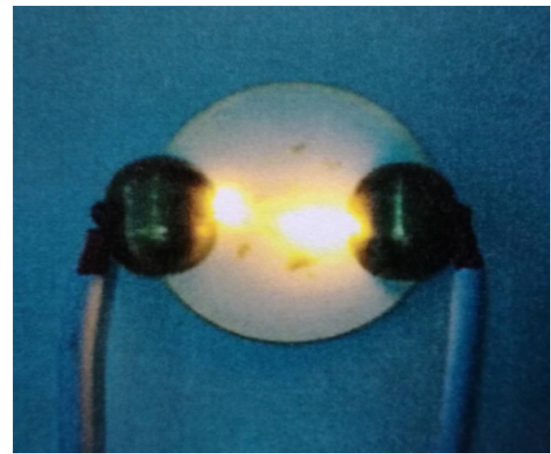

Fig. 6. Flashover through the water droplets

Figure 9 shows the variation of flashover voltage with water conductivity for two droplets of $0.05 \mathrm{ml}$ each and being one on top of the other. Figure 10 shows the variation of flashover voltage with water conductivity for the three droplets, each having a volume of $0.05 \mathrm{ml}$. Figure 11 shows the variation of flashover voltage with water conductivity for one droplet of $0.1 \mathrm{ml}$. Figure 12 shows the variation of flashover voltage with water conductivity for two droplets next to each other, each having a volume of $0.1 \mathrm{ml}$. Figure 13 shows the variation of flashover voltage with water conductivity for two droplets of $0.1 \mathrm{ml}$ each and being one on top of the other. Figure 14 shows the variation of flashover voltage with water conductivity for the three droplets, each having a volume of $0.1 \mathrm{ml}$. It must be noted that in all Figures the blue line indicates the sample with $0 \mathrm{wt} \%$ nanoparticles, the red line indicates the sample with $1 \mathrm{wt} \%$ nanoparticles, the yellowline indicates the sample with $3 \mathrm{wt} \%$ nanoparticles, the purple line indicates the sample with $5 \mathrm{wt} \%$ nanoparticles and the greenline indicates the sample with $10 \mathrm{wt} \%$ nanoparticles.

\section{DISCUSSION}

In most experiments there was an oscillation of the droplet(s), which eventually were breaking up. For the droplets arrangement of the three droplets, it was noticed that there was too often a deformation and eventual break-up of the middle droplet. In the case of the two droplets, with one next to the other, it was often observed an oscillation and eventual coming together of the two droplets. In all results, irrespective of the number and/or the volume of droplets, water conductivity seems to lower the flashover voltage. As the conductivity increases, the flashover voltage decreases. The volume of the droplets plays also an important role, i.e. the flashover voltage seems to be lower for the $0.1 \mathrm{ml}$ droplet(s) than for the $0.05 \mathrm{ml}$ droplet(s). The positioning of the droplets w.r.t. the electrodes plays also a vital role, i.e. as the distance of the droplet(s) from the electrodes becomes smaller, the flashover voltage decreases (compare for example, the results between Figures 12-13).

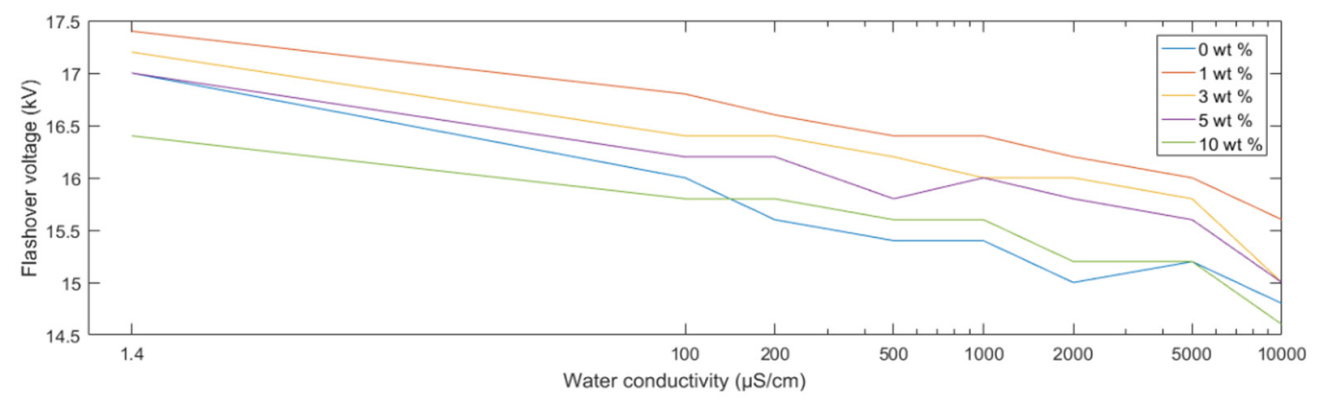

Fig. 7. Comparison of flashover voltages for one droplet of $0.05 \mathrm{ml}$

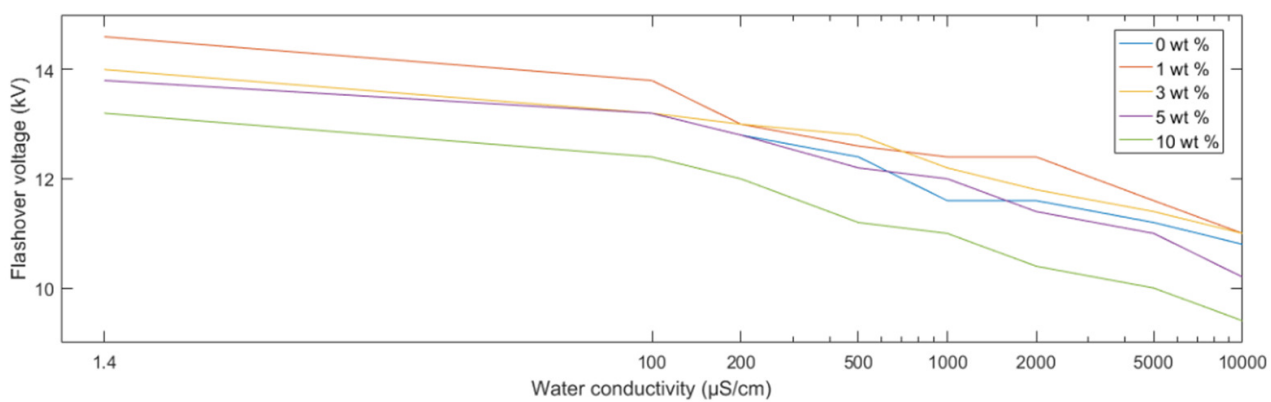

Fig. 8. Comparison of flashover voltages for two-droplets arrangement of $0.05 \mathrm{ml}$ each (one droplet next to the other) 


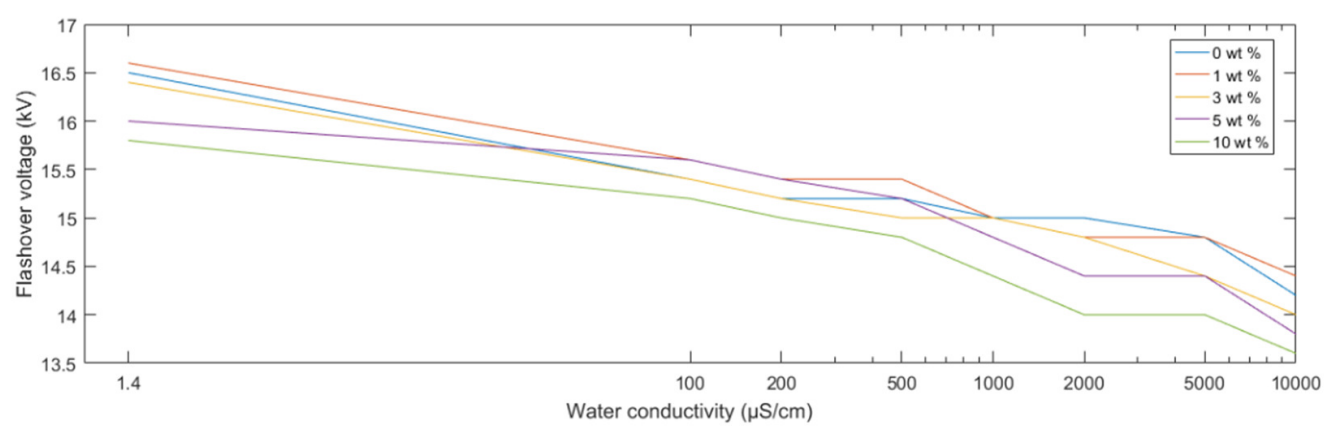

Fig. 9. Comparison of flashover voltages for two-droplets arrangement of $0.05 \mathrm{ml}$ each (one droplet on top of the other)

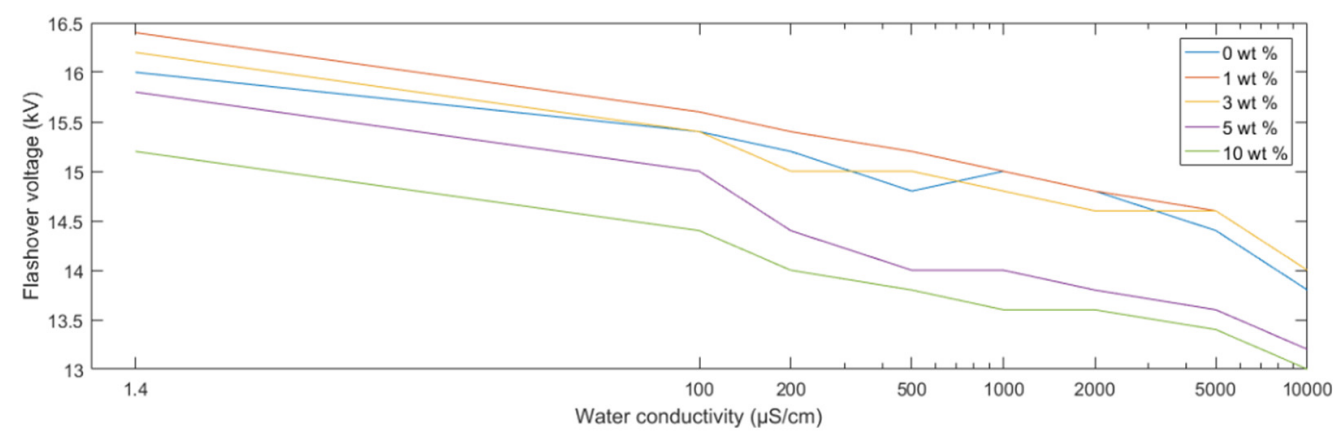

Fig. 10. Comparison of three-droplets arrangement of $0.05 \mathrm{ml}$ each

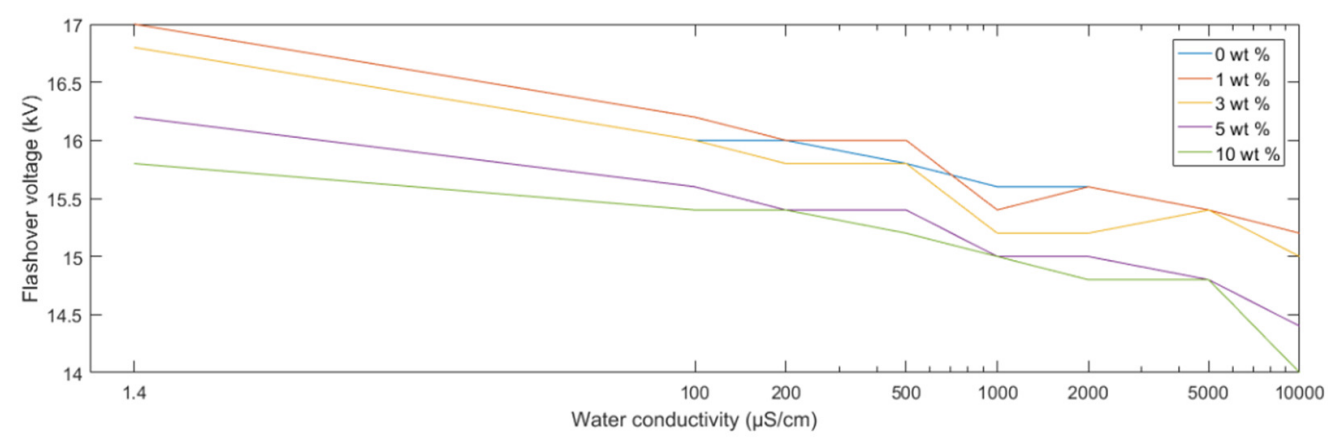

Fig. 11. Comparison of one-droplet arrangement of $0.1 \mathrm{ml}$

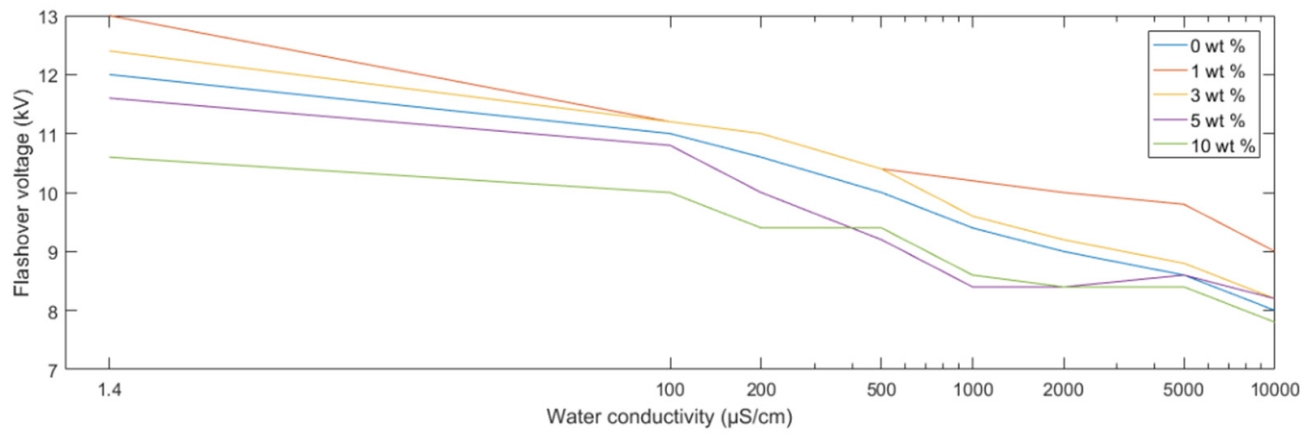

Fig. 12. Comparison of two-droplets arrangement of $0.1 \mathrm{ml}$ each (one droplet next to the other) 


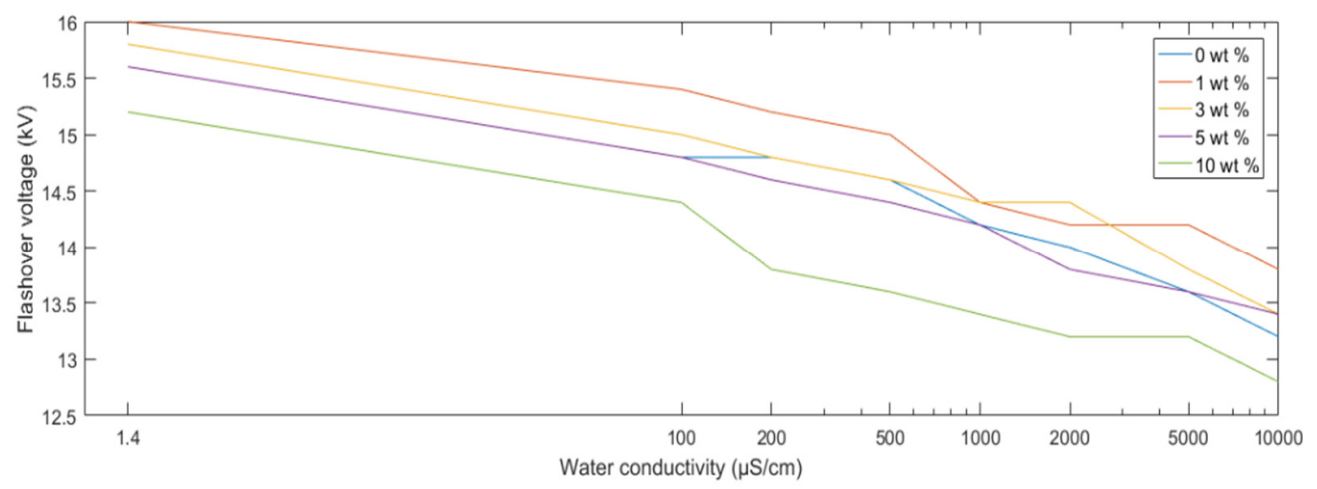

Fig. 13. Comparison of two-droplets arrangement of $0.1 \mathrm{ml}$ each (one droplet on top of the other)

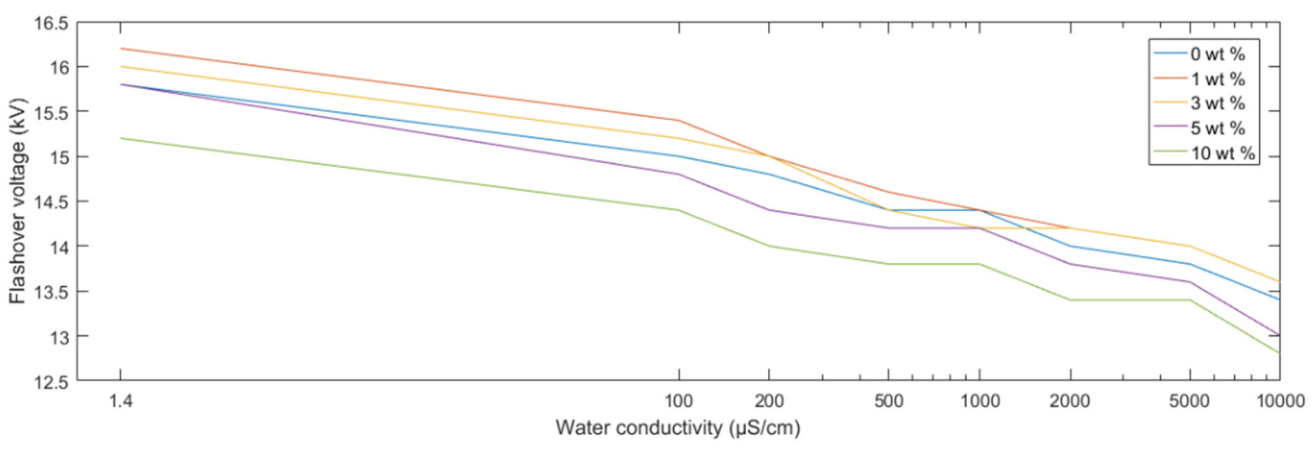

Fig. 14. Comparison of three-droplets arrangement of $0.1 \mathrm{ml}$ each

This reminds us of a similar effect with the partial discharges, where cavities next to electrodes give higher discharge magnitudes than cavities which are totally enclosed in the solid insulation [13-15]. Certainly, the proximity with the electrodes seems to initiate more easily electron emission in either case. The polymer nanocomposite surface is of great importance for the flashover data. It seems that nanocomposites with $1 \mathrm{wt} \%$ and $3 \mathrm{wt} \%$ nanoparticles have higher flashover voltages than the pure epoxy resin (with $0 \mathrm{wt} \%$ ), whereas the sample with $5 \mathrm{wt} \%$ nanoparticles has comparable flashover voltages with the pure epoxy resin. The polymer nanocomposite with $10 \mathrm{wt} \%$ nanoparticles gives the lowest results, even lower than the pure epoxy resin. The fact that polymer nanocomposites have higher flashover voltages than pure epoxy resin seems to agree with previous published research [16], where it was pointed out that the depth of erosion in pure polymers is larger than the erosion depth of polymer nanocomposites. This was attributed to the coming onto the surface of the nanoparticles and this contributes to the lowering of the surface discharges. However, as noted, a big increase of nanoparticle content does not necessarily imply the increase of flashover voltage. The $10 \mathrm{wt} \%$ nanocomposite in our experiments did not perform well, even in comparison with the pure epoxy resin. The results of the present work agree with those published before, albeit with somehow different droplet arrangements [7, 17]. It may be that, as the percentage of nanoparticles increases beyond a certain value, agglomerations of nanoparticles may appear which may be sites of further discharging and of eventual erosion of the nanocomposite surface. This explanation, however, has to be further investigated. An ever increasing percentage of nanoparticles in a polymer may not be advisable in the light of other experimental evidence, as was noted elsewhere [18, 19].

The problem of the negative effect of exceeding nanoparticle content in a polymer has to be further investigated. A lot of research has been done regarding the effect of nanoparticle agglomerations on partial discharge activity [20, 21]. It is established that nanoparticle agglomerations may hinder the electrical performance of a polymer nanocomposite and may lower its breakdown strength. However, when one comes to the surface discharge behavior of the polymer nanocomposites, relevant information is missing or it is rather scant. There are reports of improvement of flashover voltage with the addition of carbon black nanoparticles (1 wt\%) in ethyl-vinyl acetate [22]. According to the authors of [22], the improvement is attributed to the introduction of deeper traps capturing the charges and thus increasing the flashover voltage. In yet another work [23], the authors claimed that low nanoparticle content $(1 \mathrm{wt} \%)$ increases the density of deep traps and helps in improving the flashover voltage. However, with higher nanoparticle content, distances between adjacent nanoparticles decrease. Overlapped interaction zones of nanoparticles are quasi-conductive and they raise the energy level of traps. Deep traps are replaced by shallow traps and the latter contribute to charge dissipation. This in turn increases the mobility of carriers and increases the conductivity of nanocomposites. Consequently, charge carriers tend to move 
through connected interaction zones more freely and thus triggering of a surface flashover becomes more probable. The above may be an explanation as to why higher nanoparticle content lowers the flashover voltage, but it is advisable to perform further research on the subject. An interesting topic of further contemplation may be about the role of nanoparticle agglomerations, since these, although they play a negative role in internal discharges, at least according to some researchers may play a positive role for surface flashover [16]. According to [16], nanoparticles may come onto the surface after the occasional erosion, and thus may act as minute barriers against the development of either a surface discharge or a flashover. There is, however, another point of view offered in [24]. According to [24], nanoparticles coming onto the surface of the nanocomposite, may agglomerate and cause local asymmetrical fields because of their higher dielectric constant. Further work is urgently needed in order to clarify the whole mechanism. Needless to say that all the above have to be investigated in the light of the morphology of polymer matrix, of processing conditions, of lamellar thickening process, and of crystallinity [25].

The present experimental results give an idea as to the parameters affecting the water droplet behavior on conventional and nanocomposite polymeric surfaces. A better picture may emerge if there will be more experiments w.r.t. the evolution of droplets with time. It is hoped that with this kind of experiments, details of the break-up of droplets will emerge with the aid of ultra-fast photographic apparatus. Even more interesting would be the clarification of the role of nanoparticles with surface ageing, since it was reported that nanoparticles affect decisively the surface roughness during the ageing process [26]. The results of the present work point out to the influence of water conductivity, number of droplets as well as of their positioning on the flashover voltage. Relatively little influence has the surface roughness of the polymer nanocomposite, as is evident in the results presented here. The latter remark is at variance with previously published work [27] (it must, however, be noticed that in [27], different insulating materials from the ones used in this work were used). The $10 \mathrm{wt} \%$ nanocomposite has the lowest roughness but it also has the worst performance from all samples. The conclusions of the present work, regarding the above mentioned factors, agree qualitatively with previously published research [28, 29].

\section{CONCLUSIONS}

Factors that affect the flashover voltage in polymer nanocomposites are the water droplet conductivity, the number of droplets on the polymer surface and the positioning of the droplets w.r.t. the electrodes. The highest flashover voltages were noted with samples having nanoparticles in the range of 1 $\mathrm{wt} \%$ up to $3 \mathrm{wt} \%$. Such percentages agree qualitatively with experimental results of other researchers. Higher nanoparticle content may cause a decrease of flashover voltage. Whether this is due to nanoparticle agglomerations or whether it is due to some inner workings of interaction zones between the nanoparticles remains to be seen.

\section{ACKNOWLEDGMENT}

The present work was carried out with samples of epoxy resin nanocomposites, which were built at the Department of Electrical Engineering, Indian Institute of Technology Madras, India.

\section{REFERENCES}

[1] T. J. Lewis, "Nanometric dielectrics", IEEE Transactions on Dielectrics and Electrical Insulation, Vol. 1, pp. 812-825, 1994

[2] J. K. Nelson, Dielectric polymer nanocompsites, Springer, 2010

[3] T. Tanaka, "Dielectric nanocomposites with insulating properties", IEEE Transactions on Dielectrics and Electrical Insulation, Vol. 12, No. 5, pp. 914-928, 2005

[4] M. G. Danikas, "On two nanocomposite models: Differences, similarities and interpretational possibilities regarding Tsagaropoulos' model and Tanaka' s model", Journal of Electrical Engineering, Vol. 61, No. 4, pp. 241-246, 2010

[5] G. Melissinos, M. G. Danikas, "On polymer nanocomposites: Electrical treeing, breakdown models and related simulations", Engineering, Technology \& Applied Science Research, Vol. 8, No. 2, pp. 2627-2632, 2018

[6] T. Tanaka, T. Imai, "Advances in nanodielectric materials over the past 50 years", IEEE Electrical Insulation Magazine, Vol. 29, No. 1, pp. 1023, 2013

[7] S. C. Kechagia, M. G. Danikas, R. Sarathi, "Water droplets and breakdown phenomena on polymer nanocomposite surfaces under the influence of uniform electric fields", Malaysian Polymer Journal, Vol. 8, No. 2, pp. 41-48, 2013

[8] R. Gorur, "High voltage outdoor insulation technology", Control and Dynamic Systems, Vol. 44, pp. 131-191, 1991

[9] M. G. Danikas, "Surface phenomena on resin-type insulators under different electrical and non-electrical stresses in the early stage of ageing”, Facta Universitatis, Vol. 13, No. 3, pp. 335-352, 2000

[10] R. S. Sahu, Understanding the electrical, thermal and mechanical properties of epoxy nanocomposites, Ph.D. Thesis, Indian Institute of Technology Madras, Department of Electrical Engineering, Chennai, India, 2007

[11] R. Sarathi, M. G. Danikas, "Understanding discharge activity due to water droplet in epoxy nanocomposites using acoustic emission technique", Journal of Electrical Engineering, Vol. 59, No. 6, pp. 294301,2008

[12] A. Bairaktari, M. G. Danikas, X. Zhao, Y. Cheng, Y. Zhang, "Behavior of water droplets under the influence of a uniform electric field in nanocomposite samples of epoxy resin/ $\mathrm{TiO}_{2}$ ", Engineering, Technology \& Applied Science Research, Vol. 3, No. 5, pp. 511-515, 2013

[13] J. H. Mason, "Discharges", IEEE Transactions on Electrical Insulation, Vol. 13, No. 4, pp. 211-238, 1978

[14] M. S. Naidu, V. Kamaraju, High Voltage Engineering, McGraw-Hill Publishing, 2000

[15] A. A. Hossam-Eldin, S. S. Dessouky, S. M. El-Mekkawy, R. A. Abd ElAal, "Internal discharge in cavities in solid dielectric materials", Journal of Electrical Engineering, Vol. 9, No. 4, pp. 1-5, 2009

[16] M. Kozako, R. Kido, T. Imai, T. Ozaki, T. Shmizu, T. Tanaka, "Surface roughness change of epoxy/ $\mathrm{TiO}_{2}$ nanocomposites due to partial discharges", 2005 International Symposium on Electrical Insulating Materials, Kitakyushu, Japan, June 5-9, 2005

[17] S. K. Kechagia, Flashover phenomena on the surface of nanocomposite materials under the influence of uniform electric fields, MSc Thesis, Democritus University of Thrace, 2010 (in Greek)

[18] J. K. Nelson, Y. Hu, "Nanocomposite dielectrics - Properties and implications", Journal of Physics D: Applied Physics, Vol. 38, pp. 213222,2005

[19] C. Kalaivananand, S. Chandrasekar, "Understanding inception and propagation of electrical tree discharge characteristics in XLPE nanocomposites", The Journal of CPRI, Vol. 13, No. 1, pp. 111-116, 2017 
[20] M. G. Danikas, T. Tanaka, "Nanocomposites - A review of electrical treeing and breakdown", IEEE Electrical Insulation Magazine, Vol. 25, No. 4, pp. 19-25, 2010

[21] E. David, M. Frechette, "Polymer nanocomposites - major conclusions and achievements reached so far", IEEE Electrical Insulation Magazine, Vol. 29, No. 6, pp. 29-36, 2013

[22] B. X. Du, J. Li, Q. Du, M. L. Fu, "Surface charge and flashover voltage of EVA/CB nanocomposite under mechanical stresses", IEEE Transactions on Dielectrics and Electrical Insulation, Vol. 23, No. 6, pp. 3734-3741, 2016

[23] S. Yu, S. Li, S. Wang, Y. Huang, M. Tariq Nazir, B. T. Phung, "Surface flashover properties of epoxy based nanocomposites containing functionalized nano- $\mathrm{TiO}_{2}$ ", IEEE Transactions on Dielectrics and Electrical Insulation, Vol. 25, No. 4, pp. 1567-1576, 2018

[24] W. Yan, Nanocomposite dielectric materials for power system equipment, PhD. Thesis, University of New South Wales, 2013

[25] P. A. Sharad, K. S. Kumer, "Application of surface-modified XLPE nanocomposites for electrical insulation - Partial discharge and morphological study", Nanocomposites, Vol. 3, No. 1, pp. 30-41, 2017

[26] M. Liang, Long-term performance of nanocomposite in power transmission and distribution systems, PhD Thesis, RMIT University, 2018

[27] S. Maslougkas, M. G. Danikas, "Study of water droplets behavior on electrical machine insulation under the influence of uniform electric fields: The influence of some parameters on mica sheets", Engineering, Technology \& Applied Science Research, Vol. 8, No. 1, pp. 2351-2355, 2018

[28] L. Zevgolas, Y. Cheng, M. G. Danikas, R. Sarathi, "Study of the behavior of water droplets under the influence of a uniform electric field in epoxy resin samples having different $\mathrm{wt} \%$ percentages of nanoparticles and microparticles", Journal of CPRI, Vol. 13, No. 1, pp. $1-6,2017$

[29] R. Sarathi, V. Sri Harsha, N. J. Vasa, "Water droplet initiated discharges on epoxy nanocomposites under DC cvoltages", IEEE Transactions on Dielectrics and Electriocal Insulation, Vol. 23, No. 3, pp. 1743-1752, 2016 